\title{
VIOLENCIA DE GÉNERO Y TRATA DE PERSONAS CON FINES DE EXPLOTACIÓN SEXUAL. VULNERABILIDAD DE LAS MUJERES INMIGRANTES EN SU PASO POR MELILLA Y NORTE DE ÁFRICA
}

\author{
GENDER VIOLENCE AND TRAFFICKING OF HUMAN BEINGS FOR SEXUAL \\ EXPLOITATION PURPOSES. VULNERABILITY OF IMMIGRANT WOMEN \\ IN THEIR PASSAGE BY MELILLA AND NORTH OF AFRICA
}

\author{
MARÍA DEL ÁGUILA LARA PALACIOS* \\ MARÍA DEL CARMEN MONREAL GIMENO** \\ SEBASTIÁN SÁNCHEZ FERNÁNDEZ***
}

\begin{abstract}
RESUMEN
La finalidad de la investigación es visibilizar todos los ámbitos que conforman la trata de personas con fines de explotación sexual, así como la situación que viven las personas inmigrantes en su paso por el norte de África hasta llegar a Melilla. Para ello hemos utilizado una metodología comparativa de las normativas existentes a nivel internacional, europeo, nacional y autonómico de la ciudad de Melilla, junto con la información obtenida de la observación directa. Las conclusiones principales son: La trata de personas con estos fines está directamente relacionada, con las desigualdades de género llevados al extremo, roles de género asociados al sexo, los conceptos de trata de personas con estos fines y prostitución son confundidos, $y$, en la ciudad de Melilla no ha existido aún un plan de acción contra la trata.
\end{abstract}

PALABRAS CLAVE: explotación sexual, prostitución, tráfico ilegal de personas, género y sexo.

\begin{abstract}
The purpose of the research is to make visible all the areas that make up the trafficking of human beings for sexual exploitation purposes. As well as, the situation that immigrants live in their passage through North Africa to reach Melilla. We have used a comparative methodology of existing measures at international, european, national and regional level of the City of Melilla. Also, the information obtained from the direct observation. The main conclusions are: Trafficking of human beings for these purposes is directly related to gender roles in sex, the concepts of trafficking of human beings for these purposes and prostitution are confused, and, in the City of Melilla there has not yet been a plan of action against trafficking of human beings.
\end{abstract}

KEYWORDS: trafficking of human beings for sexual exploitation purposes, prostitution, illegal trafficking of persons, gender and sex.

\footnotetext{
* Doctorado en Ciencias Sociales e Intervención Social. Facultad de Ciencias Sociales. Universidad Pablo de Olavide de Sevilla, España. C/ Lérida, n4, bajo derecha. 52001. Melilla. mlarapalacios@gmail.com

** Doctora en Psicología y Ciencias de la Educación. Facultad de Humanidades. Universidad Pablo de Olavide de Sevilla, España. Carretera Utrera Kml, 41013. Sevilla. mcmongim@upo.es

*** Doctor en Ciencias de la Educación. Facultad de Educación. Universidad de Granada en Melilla, España. C/ Santander $n^{\circ}$ 1. 52005. Melilla. ssanchez@ugr.es
} 


\section{INTRODUCCIÓN}

El fenómeno de la trata, considerado como la "nueva esclavitud del siglo XXI" constituye una forma de explotación que increíblemente no solo está decayendo sino que aumenta. $Y$ además, no constituye un fenómeno aislado, sino generalizado a muchos países del mundo, sobre todo en sociedades desarrolladas.

No obstante, la percepción que se tiene sobre este grave delito es que este fenómeno está alejado de la vida diaria, difícil de encontrar y residual. Lo que es cierto es que el fenómeno de la trata ha sufrido transformaciones importantes en los últimos tiempos, además de haber aumentado considerablemente dados los inmensos beneficios económicos que se producen a partir del sufrimiento de las víctimas.

Una de las causas de esta invisibilidad se debe precisamente a estas transformaciones ocurridas en todo el mundo globalizado en el que las comunicaciones son más fáciles y cercanas. Hasta el siglo XX, se asociaba este fenómeno a las mujeres blancas "trata de blancas", mujeres y niñas de occidente eran raptadas y llevadas a oriente como objeto exótico para explotación sexual y era un fenómeno minoritario. Pero actualmente, todas las mujeres pueden ser susceptibles de ser captadas para ser explotadas independientemente de su procedencia, raza y etnia.
En este proceso migratorio, las mujeres y niñas, además de compartir los peligros que afectan a sus compañeros de viaje por las mafias que intentan sacar beneficio de estas personas, son violadas y muchas de ellas acaban en redes de trata de personas. Otras son captadas en su propio país al ser engañadas con falsas promesas de trabajo y ellas ante la esperanza de una vida mejor inician un viaje que raras veces tiene retorno.

\section{REVISIÓN BIBLIOGRÁFICA, METODOLOGÍA UTILIZADA Y OBJETIVOS}

El diseño de esta investigación se planificó en dos fases: Una primera que comprendió el conocimiento de los contextos socioculturales tanto de la ciudad de Melilla como de la ciudad de Nador ${ }^{1}$ (Marruecos), y una segunda parte de revisión bibliográfica.

Para la adquisición del conocimiento de los contextos socioculturales indicados empleamos una metodología cualitativa. Desarrollamos una observación no participante. Los instrumentos utilizados fueron entrevistas semiestructuradas y el diario de campo.

Entrevistamos a las personas responsables de todas las ONG presentes en ambas ciudades que trabajan en el ámbito de

\footnotetext{
Nador es la ciudad fronteriza de Marruecos con Melilla donde se encuentran los asentamientos de personas inmigrantes que intentan alcanzar la ciudad española. Es su último paso para ello.
} 
la inmigración, al jefe de la UCRIF², al consejero de Bienestar Social de la ciudad de Melilla, los directores del hospital Comarcal de esta misma ciudad y del hospital Hassani de Nador y al director del $\mathrm{CETI}^{3}$.

En el CETI también entrevistamos a la médica responsable de la unidad sanitaria, a la trabajadora social y a la psicóloga. Asimismo, al director del Centro de Salud donde son derivadas las personas residentes del CETI.

Además, en Nador entrevistamos al director de Sanidad e Higiene de la ciudad. Por otro lado, visitamos los asentamientos de las personas inmigrantes.

Con la primera fase pretendíamos conocer las prácticas que se desarrollan para garantizar los Derechos Humanos de las personas migrantes tanto en la ciudad de Melilla como en la ciudad Nador. Y en concreto, de las mujeres inmigrantes.

El diario de campo nos sirvió para nutrirnos de los datos que íbamos recabando, así como elaborar ideas para sistematizar nuestros próximos pasos en esta investigación.

En cuanto a la segunda fase de la investigación, la revisión bibliográfica ha sido realizada de manera muy exhaustiva. Se han revisado todas las normativas de trata de personas publicadas a nivel internacio-

2 UCRIF: Unidad Central de Redes de Inmigración llegal y Falsedades Documentales.

3 CETI: Centro de Estancia Temporal de Inmigrantes. nal, europeo, nacional y autonómico de la ciudad de Melilla. Se ha utilizado una metodología comparativa en todas ellas para detectar duplicidades, lagunas y posibles incoherencias entre los objetivos a alcanzar por estas normativas y las medidas registradas a desarrollar para conseguirlos.

Hemos considerado qué tan importante es ver y conocer las prácticas que se desarrollan en terreno, en una ciudad-frontera como es Melilla, como conocer las normativas registradas en la materia que nos ocupa.

La finalidad de esta investigación es tener incidencia social-política al influir en futuros planes de prevención y lucha contra la trata de personas más adecuados, que garanticen los Derechos Humanos de las personas.

Los objetivos perseguidos con el análisis realizado han sido:

- Explicar los fenómenos de violencia de género y trata desde las creencias patriarcales.

- Analizar los conceptos de trata de seres humanos con fines de explotación sexual a la luz de la normativa internacional y nacional.

- Identificar los Derechos Humanos Universales vulnerados en la trata de personas con fines de explotación sexual.

- Visualizar la situación de las personas migrantes en Melilla y en su entorno geográfico. 


\section{VIOLENCIA DE GÉNERO Y TRATA}

La sociedad patriarcal ha delimitado claramente cuáles son las características psicológicas que corresponden a hombres y mujeres, y en virtud de ello, los roles que deben desempeñar en la sociedad. En este contexto de delimitación de espacio y funciones, la violencia de género se convierte en un vehículo para el control de las mujeres. Esta -de forma real o su amenaza - funciona como un metalenguaje, nada sutil por el que se ha señalado a la mujer cuál era su sitio: el ámbito privado, del hogar y de lo doméstico, por oposición al espacio público, que los hombres se reservaban para sí.

En consecuencia, podemos apreciar una conexión cultural entre "masculinidad" y práctica heterosexual en un contexto de dominación masculina en todos los órdenes: económico, social, político, ideológico, que ha favorecido la impunidad de los abusos sexuales de las mujeres. Este hecho responde a que, frecuentemente, se ha asociado "agresión sexual" y "masculinidad" de modo que la violación ha sido asimilada a una actividad sexual ligada a la "hombría" y no primordialmente como una actividad violenta.

Por añadidura, esta asociación entre masculinidad y heterosexualidad confiere al acto de violar un alto valor simbólico, ya que, detrás de la obsesión por la conquista subyace el hecho de que el hombre debe probar su masculinidad, mientras que la identidad femenina ha sido construida históricamente como carente de una sexualidad propia, surgiendo el binomio del hombre activo/mujer pasiva: El hombre que conquista y la mujer que se resiste (como corresponde a su papel), pero que en realidad quiere ser conquistada: "Cuando dicen no, quieren decir sí".

En consecuencia, la violencia contra las mujeres solo puede ser entendida dentro de una concepción de la mujer como una propiedad masculina, que puede usar el varón según le apetezca. Este modelo androcéntrico de sexualidad es el que ha dificultado la comprensión a una parte de la sociedad, así como a la clase jurídica, la posibilidad y gravedad de la violación dentro del matrimonio.

El modelo androcéntrico comporta unos determinados rasgos: coitocentrista, prima la cantidad frente a la calidad de los encuentros sexuales, deseo sexual masculino incontrolable, negando la posibilidad de una sexualidad femenina autónoma guiada por la propia iniciativa.

En este marco cultural es difícil entender, como se sostiene desde una perspectiva feminista, que la esencia de la violación consiste, no tanto en tener una relación sexual con una persona, sino en "su realización por la fuerza”, contra su voluntad, lo que demuestra hostilidad y desprecio frente al sexo femenino. Como ya hemos apuntado, esta actitud puede provenir de diversos factores, entre ellos, del proce- 
so de socialización en un sentido amplio en el que se inculca que ser hombre en la sociedad patriarcal, es ser importante porque las mujeres no lo son. Señala Josep-Vicent Marques que el varón socializado por el patriarcado tiende a relacionarse solo o primordialmente con varones; no suele percibir a la mujer real sino por medio de estereotipos que la "sobre o infravaloran", mostrando resistencia a aceptar estar en el mismo plano que las mujeres (Marques y Osborne, 1991, p.48).

Esto implica una mentalidad en la que no hay reciprocidad, la mujer no es vista en un plano de igualdad, por lo que se propician unas pautas de conquista que tienen que ver con:

a. La idea de que todas las mujeres, excepto las propias son unas putas, $\mathrm{y}$

b. La radical separación entre sexo y amor o ternura que resulta ser parte integral de la socialización masculina.

Las mujeres han aprendido, por prescripción social a justificar su deseo con amor; solo pueden aceptar ante sí mismas y ante los demás una relación sexual si están enamoradas.

Como consecuencia de este proceso de socialización en el que se integran las creencias y estereotipos que corresponden a uno u otro grupo social, hombres y mujeres, a los hombres les corresponde decidir porque son los inteligentes y a las mujeres obedecer y querer; de ahí que deban ser sumisas y afectivas. Estos as- pectos de los estereotipos transmitidos subyacen a las agresiones sexuales y los podríamos agrupar en:

- Producto inevitable de las necesidades sexuales masculinas = impulso irrefrenable.

- Rasgo inherente a la categoría de ser mujer, algo que se puede hacer a la mujer por el mero hecho de serlo.

- Como una consecuencia casi lógica del modelo que ve como normal en los varones una cierta dosis de agresividad en su conducta, como si fuera parte inherente de la masculinidad una cierta dosis de violencia, de modo que los niños que son muy brutos son sospechosos de no ser muy hombres.

Todos estos aspectos recogen la idea de la superioridad de los hombres en todos los órdenes, especialmente en su relación con las mujeres, y engloban la creencia de que para dominar, a veces hay que intimidar y coaccionar.

En suma, los vínculos entre las agresiones contra las mujeres y las pautas de conducta aprobadas socialmente, en cuanto a las normas derivadas de los estereotipos masculino/femenino, nos ayudan a comprender mejor la falta de sensibilidad o incluso la tolerancia general hacia la violencia contra las mujeres y el hecho de que las violaciones pueden ser cometidas por cualquier tipo de varones con cualquier tipo de mujeres, así como en cualquier lugar y momento. 
Estos patrones de comportamiento no se improvisan, son fruto de la historia y de la cultura y se reproducen por medio de la socialización en la desigualdad entre los sexos y, en una radical división del deseo que en el hombre se desliga el sexo del amor, mientras que la mujer no. Si la desigualdad implica la consideración de la mujer como un objeto y si el sexo se desliga del amor, empezaremos a comprender cómo se generan "las semillas de la violencia" (título de una obra de Luis Rojas Marcos).

Con estas creencias entendemos cómo la trata con fines de explotación sexual se extiende fundamentalmente a la población de mujeres y niñas y en cierto modo, se justifica. Las mujeres, de este modo, han llegado al extremo de la desigualdad: cosificación y abuso de ellas.

A partir de los años 80 comenzó el reconocimiento internacional de la gravedad del problema de la violencia contra las mujeres (III Conferencia de Naciones Unidas sobre la mujer, Nairobi, 1985), si bien los antecedentes de denuncia de esta situación se remontan a los orígenes del movimiento feminista contemporáneo, sobre todo de los años 70.

Poco a poco, la puesta en común de las experiencias de estas mujeres puso de relieve la problemática de las agresiones o del miedo a las agresiones, que muchas mujeres experimentan en sus vidas. Es más, la propia búsqueda y necesidad de ma- yor libertad sexual hizo que se resaltara la violencia sexual como una de las vías, por las que esa libertad era coartada. La lucha contra las agresiones era una forma de mostrar la victimización de las mujeres, al mismo tiempo que se manifestaba la voluntad de combatirla. Semejante violencia se interpretó como una coacción para el conjunto de las mujeres, a las que se podía agredir o amenazar con agredir sexualmente, si no se conformaban a una serie de normas destinadas a consolidar la división entre buenas y malas mujeres. Las primeras pertenecían a un solo hombre, preferiblemente a través del matrimonio, no salían solas a ciertas horas, no adoptaban actitudes provocativas o insinuantes. Las segundas ya sabían a qué se exponían si no se atenían a estos mandatos.

Cuando las feministas aunaron sus reflexiones y sus esfuerzos, invirtieron el énfasis que tendía a culpar a las mujeres por las agresiones que sufrían y a absolver a los hombres de su responsabilidad hacia la víctima. Denunciaron una mentalidad patriarcal en tanto ha tolerado, disculpado o banalizado este comportamiento de los hombres y que ha llegado incluso a incrustarse en las Instituciones Sociales, una mentalidad que ha contribuido a mantener la dominación de los hombres sobre las mujeres.

Por agresión sexual entendemos cualquier tipo de actividad sexual cometida contra el deseo de una persona, ya sea con 
utilización efectiva, o amenaza de utilización de la fuerza, o por imposición de la voluntad del agresor por cualquier otro medio (distinta de la definición jurídica que distingue entre agresiones y abusos sexuales, no requiriendo estos últimos de la fuerza física que hace que no se les catalogue como delitos). Nos interesa destacar el elemento de la coerción sexual sin precisar el medio empleado para imponer sobre otra persona una actividad sexual que no desea.

A través de los datos obtenidos de las denuncias se sabe que las mujeres agredidas pertenecen a todas las clases sociales, son violentadas en todas las edades, desde niñas hasta ancianas. Si bien la frecuencia es más alta entre las jóvenes, por las mayores posibilidades que cuentan los violadores por la mayor movilidad física y horaria.

En la violación se conjugan dos elementos superpuestos: La agresión y el sexo. Hasta hace poco se consideraba este último aspecto el componente central de esta acción. Actualmente y gracias a la argumentación feminista, se entiende como un acto básicamente violento y coercitivo, que desencadena una acción de hostilidad hacia la mujer entendida en sentido genérico.

La violación constituye un proceso consciente de intimidación por el que todos los hombres mantienen a todas las mujeres en un estado de miedo. Esta idea fue aceptada pronto más allá de los círculos feministas (Brownmiller, 1975, p.5). A pesar de que en las sociedades modernas no se practica la dominación por la fuerza, esto no quiere decir que el miedo o la coacción no sea utilizada para restringir la libertad de la mujer. De hecho, cuando se esgrime que la violación constituye un atentado contra la libertad individual y colectiva de las mujeres, se está queriendo resaltar la forma en que, no solo el hecho de la violación sino el temor a ser violadas, representa una constatación palpable de la devaluación, objetualización y carencia de autonomía de las mujeres, lo que actúa como mecanismo de sujeción al control masculino.

\section{COMPARACIÓN DEL CONCEPTO}

DE “TRATA DE SERES HUMANOS CON FINES DE EXPLOTACIÓN SEXUAL" CON LOS DE “PROSTITUCIÓN"

Y “TRÁFICO DE PERSONAS”

A menudo el concepto de trata de personas con fines de explotación sexual es confundido con los de prostitución y de "tráfico de personas". Por ello, antes de abordar la trata desde la perspectiva de los Derechos Humanos Universales, nos acercaremos al concepto de "trata" estableciendo una comparación con los términos de "prostitución" y de "tráfico ilegal de personas".

La invisibilización que ha caracterizado, hasta hace relativamente poco tiempo, 
a la trata de personas con fines de explotación sexual se debe en parte a la confusión en la concreción y concisión en la definición del término, la que ha provocado que la trata de personas sea asimilada al tráfico ilegal o al ejercicio de la prostitución. Esto ha supuesto la falta de un reconocimiento específico del problema, así como la puesta en marcha de herramientas y estrategias que permitan enfrentarlo con toda su complejidad.

En cuanto a la normativa existente en el ámbito europeo, tanto el Convenio del Consejo de Europa (2005, p.5) (art. 4) como la Estrategia de la UE para la erradicación de la trata de seres humanos (20122016) toman la definición de trata de personas del Protocolo para prevenir, reprimir y sancionar la trata de personas, especialmente mujeres y niños ${ }^{4}(2000$, p.2) (Art. 3).

En el ámbito nacional, el Plan Integral de lucha contra la trata del Ministerio del Interior (2007, p.5) y el Plan Integral contra la trata de seres humanos (2009, p.11) toman la definición de trata de seres humanos con fines de explotación sexual registrada en el Protocolo de Palermo (2000, p.2) (Art. 3).

El Plan Integral de lucha contra las mujeres y niñas con fines de explotación sexual (2015, p.7) toma la definición de trata del artículo 177 bis del Código Penal. Dicho artículo supone el registro de la defini-

4 De ahora en adelante denominado Protocolo de Palermo (2000). ción de trata de personas del Protocolo de Palermo en el Código Penal del Estado Español.

En el ámbito internacional, el Protocolo de Palermo (2000) es el resultado de la iniciativa de la Convención de Naciones Unidas contra la delincuencia organizada trasnacional. En diciembre de 2000, en la ciudad de Palermo (Italia), 147 países firman la Convención de las Naciones Unidas contra la Delincuencia Organizada Trasnacional, que contaba además con dos instrumentos complementarios: El Protocolo para prevenir, reprimir y sancionar la trata de personas, especialmente mujeres y niños; y, el Protocolo contra el tráfico ilícito de migrantes por tierra, mar y aire.

En el Plan Integral de intervención contra la trata de personas del Protocolo de Palermo (2000) es recogida la definición de trata de seres humanos.

En esta definición destacan tres aspectos fundamentales. Son:

- La acción: La captación, transporte, embarque o recepción de personas.

- Los medios empleados: La amenaza, fuerza, engaño, abuso de poder, vulnerabilidad, pago o remuneración a alguien que ejerza un control previo sobre la víctima.

- La finalidad: El propósito de explotación tanto de tipo sexual como mediante trabajos forzados, esclavitud y prácticas similares o extracción de órganos. 
El concepto de trata de personas, no pocas veces es asimilado al de tráfico de personas o tráfico ilícito de inmigrantes, y esto sucede, entre otras cuestiones, porque la expresión tráfico de personas ha sido traducida literalmente al español del término en inglés trafficking in persons.

Los factores que nos permiten diferenciar ambos conceptos son:

- Consentimiento: El tráfico ilegal de personas implica su consentimiento a ponerse en manos de la red de traficantes. La trata de seres humanos nunca es consentida o, de haber mediado consentimiento inicial, se ha producido mediante coacción, engaño o abuso.

- Explotación: El tráfico ilegal de personas termina con la llegada de los traficados a su destino. La trata de seres humanos implica una posterior explotación de las víctimas con la finalidad de obtener beneficios económicos.

- Transnacionalidad: El tráfico ilegal de personas es siempre trasnacional mientras que la trata de seres humanos puede producirse entre distintas zonas de un mismo país.

Además del tráfico ilícito existe otro concepto que está relacionado con la trata de personas y que conviene aclarar, como es el de prostitución. Consideramos que una definición clara y concisa de ambos ayuda a diferenciarlos. siguiendo las referencias del Defensor del Pueblo, se puede afirmar que no existe una norma jurídica estatal que establezca un concepto legal de prostitución. Constituye un elemento normativo de valoración social integrado en los artículos 187 y 188 del Código Penal español; se refiere a la actividad a la que se dedica quien mantiene relaciones sexuales con otras personas a cambio de dinero (Defensor del Pueblo, 2012, p.97).

Hasta el año 2010, el Código Penal español recogía los artículos 188 y 318 bis 2 sobre la explotación de la prostitución ajena. Concretamente, el artículo 188 mencionaba la pena de prisión de 2 a 4 años para la persona que, empleando violencia, engaño o una situación de superioridad, obligara a ejercer la prostitución a otra persona mayor de edad. Por su parte, el artículo 318 bis 2 penaba a la persona que promoviera o facilitara el tráfico ilegal de otras personas con fines de explotación sexual con 5 a 10 años de cárcel.

La Ley Orgánica 5/2010, de 22 de junio, por la que se modifica la Ley Orgánica 10/1995 de 23 de noviembre, del Código Penal, crea por primera vez el "Título VII bis, De la trata de seres humanos”, añade el artículo 177 bis el que se recoge las penas de prisión para las personas que formen parte de la trata de seres humanos como reos.

Con respecto al concepto de prostitución y Ser víctima de trata con fines de explotación 
sexual implica ejercer la prostitución; sin embargo, conviene dejar claro que ser prostituta no tiene por qué implicar ser víctima de trata. La confusión en la identificación de ambos conceptos en uno, solo conlleva la dificultad de identificación de las víctimas de trata.

La identificación de los términos de trata con fines de explotación sexual y prostitución se pone de manifiesto en el Plan integral de lucha contra la trata de seres humanos con fines de explotación sexual (Ministerio del Interior, 2007),

No se puede desvincular el fenómeno de la trata del de la prostitución. (p.4)

La trata de mujeres, niñas y niños existe porque existe la prostitución. (p.11)

Finalmente, en este último documento (Ministerio del Interior, 2007) a nivel nacional, así como a nivel local mediante ordenanzas municipales ${ }^{5}$, se persiguen los actos de prostitución dejando pasar por alto la identificación de las víctimas de trata. Se puede afirmar, por tanto, que la trata de personas con fines de explotación sexual ha sido identificada con la prostitución, quizás, por su visualización en el escenario público a través de sus fines de explotación sexual.

\section{LA TRATA DE SERES HUMANOS} CON FINES DE EXPLOTACIÓN SEXUAL DESDE LA PERSPECTIVA DE LA DECLARACIÓN UNIVERSAL DE LOS DERECHOS HUMANOS

La trata de seres humanos no puede ser reducida meramente a un problema de migración ilegal, de orden público, de delincuencia organizada o prostitución para estudiar y proyectar un plan de acción para combatirla; debe integrar todos los ámbitos que comprende, y tener presentes los Derechos Humanos Universales. Todo plan de acción contra la trata de seres humanos que se planifica y ejecuta sin tener en cuenta todos los ámbitos que reúne, no dispondrá de la capacidad suficiente para identificar a las víctimas propias de la trata. Y por consiguiente, a ellas no les serán dispensadas su correspondiente asistencia y protección, adecuadas a sus necesidades.

A este respecto, las características de la definición de $\mathrm{TSH}^{6}$ recogida en el Protocolo de Palermo (2000, p.2) vulneran algunos de los Derechos Humanos Universales. Ellas son: El uso de la amenaza, de la fuerza, coacción, fraude, engaño, abuso de poder o de situaciones de vulnerabilidad, o mediante pago para obtener el consentimiento de la víctima.

5 Como es el caso de las ordenanzas municipales de las ciudades de Sevilla y Melilla a modo de ejemplo.

6 TSH: Trata de seres humanos. 
Estas características suponen la violación de todos los Derechos Humanos reconocidos en la Declaración Universal. Sirvan como ejemplo claro las referencias a los primeros artículos de la Declaración Universal7:

- Artículo 1: "Todos los seres humanos nacen libres e iguales en dignidad y derechos (...)".

- Artículo 5: "Nadie será sometido a torturas ni a penas o tratos crueles, inhumanos o degradantes", y,

- Artículo 2: "Toda persona tiene todos los derechos y libertades proclamados en esta Declaración, sin distinción alguna de raza, color, sexo, idioma, religión, opinión política o de cualquier otra índole (...)".

Además, el propósito de explotación de las personas víctimas de trata; en este caso de estudio con fines de explotación sexual. La trata supone una forma de esclavitud, y por tanto, la privación a la libertad y seguridad de las personas.

De hecho, el Consejo de Europa (2005, p.3) considera "la trata de seres humanos como una situación de esclavitud para las víctimas".

Por otro lado, muchos son los testimonios que han sido recogidos en diversas investigaciones en los que las víctimas de trata entrevistadas relataban su historia privada de libertad. Son los casos de Iri-

7 Todos los Derechos Humanos Universales han sido recuperados de https://www.un.org/es/ universal-declaration-human-rights/ na (Instituto Andaluz de la Mujer, 2011, p.91) y Susana (Instituto Andaluz de la Mujer, 2011, p.92).

El propósito de explotación de las personas en la trata supone tales vulneraciones de derechos que aparecen claramente explícitas en el Artículo 4, es decir, "la esclavitud y la trata de esclavos están prohibidas en todas sus formas".

En la práctica, y dependiendo de las circunstancias, las víctimas de trata también tienen vulnerados otros derechos. Algunas de estas circunstancias pueden ser:

- Las víctimas de trata son sometidas en numerosas ocasiones a daños físicos para que cedan a ser explotadas. Además, son amenazadas con hacerles daño a sus familias si se niegan. Por tanto, es vulnerado el Derecho Universal número 12: "Nadie será objeto de injerencias arbitrarias en su vida privada, su familia, su domicilio o su correspondencia".

- Las víctimas de la trata transnacional cruzan las fronteras de otros países ajenos al suyo, de origen de manera irregular, lo que las sitúa en una mayor vulnerabilidad por no conocer el contexto sociocultural y por carecer de redes de apoyo.

Estas circunstancias encuentran su eco en los siguientes artículos de la Declaración Universal:

- Artículo 7: “Todos son iguales ante la ley y tienen, sin distinción, derecho a igual protección de la ley”. 
- Artículo 13: "Toda persona tiene derecho a circular libremente y a elegir su residencia en el territorio de un Estado", $\mathrm{y}$

- Artículo 22: "Toda persona tiene derecho a la seguridad social, y a obtener, mediante el esfuerzo nacional y la cooperación internacional, la satisfacción de los derechos económicos, sociales y culturales, indispensables a su dignidad".

Como última reflexión consideramos que los planes de acción de lucha contra la trata de personas con fines de explotación sexual deberían recoger medidas de detección, lucha, prevención y protección poniendo en valor todos y cada uno de los Derechos Humanos Universales vulnerados.

\section{SITUACIÓN DE MELILLA Y NORTE DE ÁFRICA}

Ni el gobierno de la Ciudad Autónoma ni la Delegación del Gobierno disponen de un plan de detección, prevención, lucha y protección contra la trata de personas en general.

El Decreto No. 266 de fecha de 5 de mayo de 2015, relativo a la aprobación definitiva del Reglamento para la garantía de la convivencia ciudadana y la protección del espacio urbano en la Ciudad Autónoma de Melilla recoge en su Título II, Limpieza del espacio público; capítulo VI: Usos inadecuados del espacio público; sección primera: Normas de conducta; artículo 36: Normas de conducta; en sus puntos 1 y 5 (pp.2738-2739) lo siguiente:

- Punto 1: "Se prohíben aquellas conductas que, bajo la apariencia de mendicidad o bajo formas organizadas, representen actitudes coactivas $o$ de acoso, u obstaculicen e impidan de manera intencionada el libre tránsito de los/as ciudadanos/as por los espacios públicos".

- Punto 5: "Se prohíben las prácticas sexuales y el ofrecimiento, solicitud, negociación y aceptación directa o indirecta de servicios sexuales en la vía pública, cuando (...) se lleven a cabo en espacios situados a menos de doscientos metros de centros docentes, educativos, parques infantiles, zonas residenciales o de cualquier otro lugar en el que se realicen actividades comerciales o empresariales".

Con respecto al punto número 1 :

La mendicidad, bajo formas organizadas o no, está recogida en la definición del Protocolo de Palermo (2000, p.2) como forma de trata de personas, así como si esta tiene lugar bajo formas coactivas o de acoso. Por tanto, el Decreto No. 266 recoge parte de tal definición.

Con respecto al punto número 5 :

El ofrecimiento, solicitud, negociación y aceptación directa o indirecta de servicios sexuales pueden estar incluidos en la explotación con fines sexuales, como es en el caso de la trata con estos fines (Palermo, 2000, p.2). 
Lo sorpresivo en este punto es que estas prácticas sexuales sean prohibidas solo cuando afecten la convivencia ciudadana, tal y como es recogido en este punto. Consideramos que deberían estar prohibidas tales prácticas sea que afecten la convivencia ciudadana o no.

En el segundo párrafo de este punto 5 son descritos los espacios donde están prohibidas las prácticas sexuales recogidas, lo que conlleva a pensar que el objetivo de ello es desplazar estas prácticas de lugar, pero no combate su ejercicio.

Por otra parte, el Protocolo Interinstitucional de actuación en materia de violencia de género de la Ciudad Autónoma de Melilla (2014) en su apartado 11.3, denominado "mujeres extranjeras en situación de irregularidad documental", recoge que en los casos en los que una mujer extranjera en situación irregular denunciara una situación de violencia de género, no se incoará el procedimiento administrativo sancionador por encontrarse irregularmente en territorio español (Viceconsejería de la Mujer, 2014, p.81).

Según este protocolo las mujeres extranjeras que se encuentren inmersas en una red de trata podrán realizar la denuncia oportuna de la situación que viven sin el temor de ser detenidas y/o repatriadas. Sin embargo, este protocolo no contempla medidas específicas para las mujeres que puedan encontrarse bajo estas redes. Por tanto, no recoge medida alguna para poder ayudar a estas víctimas a realizar dicha denuncia y poder salir de su situación de explotación.

El Plan Local de Inclusión Social de la Ciudad de Melilla 2013-2014 recoge en su objetivo general 4, apoyar la integración social de los inmigrantes, unas medidas prioritarias. Estas son:

- Promover los elementos socializadores que faciliten la integración social de los inmigrantes.

- Realizar actuaciones de prevención y atención a los inmigrantes en situación de necesidad (Consejería de Bienestar Social, 2013, p.79).

Con respecto a la medida número 2, pudiera pensarse que recogía algunas actuaciones enfocadas a poder detectar y prevenir situaciones de trata de personas. Pero solo recoge 2 actuaciones. Una de ellas está en la línea de estudiar la renovación y mejora de ayudas, convenios y subvenciones destinadas a las entidades que realizan atención humanitaria a personas inmigrantes. O sea, deriva la responsabilidad de la atención directa a estos colectivos de personas a las ONG. La otra actuación a desarrollar, comprende facilitar el acceso de la población inmigrante, a las actividades de promoción de la salud y de prevención de la enfermedad (Consejería de Bienestar Social, 2012, p.81).

La entrada de las personas migrantes a Melilla se realiza según el país de origen. Las 
personas sirias o procedentes de países del Próximo Oriente suelen entrar por el puesto fronterizo internacional de Beni-Enzar sorteando a la policía marroquí o pagando a mafias que realizan tráfico ilegal de personas previo pago.

Las personas subsaharianas suelen hacer su entrada de varias maneras: Los varones, intentan saltar la valla ${ }^{8}$; las mujeres suelen hacerlo en pateras o sorteando su entrada a pie, caracterizadas como las mujeres musulmanas de la zona a través del paso fronterizo de Beni-Enzar'. Esto es así porque se requiere de una gran condición física para poder saltar la valla.

Las personas migrantes que logran llegar a Marruecos intentan mantenerse en el anonimato; si son interceptadas por la policía son llevadas a Rabat para ser expulsadas. Las personas sirias suelen estar en hostales. Las personas inmigrantes subsaharianas suelen acampar en los montes de Nador ${ }^{10}$. Allí intentan sobrevivir de la mendicidad y con la atención médica de urgencia facilitada por la Delegación de Migraciones del Servicio Jesuita.

Esta Delegación desarrolla su servicio en el turno de mañana de lunes a viernes de la siguiente manera: Diariamente dos furgonetas-dispositivos realizan una

8 Solo hubo un caso de una mujer subsahariana que saltó y lo logró hace 3 años, "Mamá África”.

9 Este es el paso fronterizo internacional. En Melilla existen cuatro: El de Mariguari, Barrio Chino, Farhana y el de Beni-Enzar.

10 Capital de la región norte del Reino de Marruecos. ruta y van visitando los distintos campamentos, de esta manera son detectados los casos que son de urgencia sanitaria y los que requieren una cita médica con un doctor de cabecera. Los primeros son enviados al Hospital Hasaní, -donde son tratados/as con los mismos recursos que una persona con nacionalidad marroquí11-; los segundos son trasladados/as al centro médico más cercano. Además, las personas sanitarias del equipo de la Delegación, les proporcionan a cada comunidad un número de teléfono para urgencias; hay que tener en cuenta que muchas de las mujeres que habitan estos montes se encuentran embarazadas.

Las personas inmigrantes que no son subsaharianas, y logran sortear el paso fronterizo marroquí, suelen solicitar protección internacional en las oficinas de la Policía Nacional del puesto fronterizo español de Beni-Enzar. En estos momentos, estas personas son entrevistadas por un/a policía acompañado/a de un/a traductor/a y un/a abogado/a de oficio. En muchas ocasiones, en estas entrevistas está presente alguna persona del equipo del $\mathrm{ACNUR}^{12}$. Las entrevistas son enviadas al Ministerio del Interior, quien resuelve al respecto.

El primer paso a su llegada al CETI consiste en someterse a varios procesos de mane-

11 En esta situación hay que resaltar que este hospital carece de las medidas básicas de higiene y de los recursos y materiales básicos de enfermería.

12 Alto Comisionado de Naciones Unidas para los Refugiados. 
ra obligatoria: una entrevista realizada por algún/a trabajador/a social. En esta se realiza una tarjeta con un número de identificación y foto para poder entrar y salir del CETI. Además, se les asigna una habitación y se les entrega una bolsa con ropa y calzado. Seguidamente, tienen que pasar el proceso en Comisaría donde son identificados y son revisados sus antecedentes penales.

Además, todas las personas que son residentes del Centro tienen que participar en un reconocimiento médico. Este consiste en una analítica denominada "perfil África" que comprende un análisis de sangre, análisis del VIH, hepatitis $\mathrm{C}$ y cultivo de esputo para la detección de tuberculosis. También, las personas residentes en el CETI tienen que asistir a unos talleres sobre normas de convivencia y hábito saludables.

En el Centro diferentes Organizaciones No Gubernamentales realizan distintas funciones: Cruz Roja lleva los servicios de enfermería y el de psicología; Melilla realiza actividades de cerámica; manualidades e informática; Accem desarrolla la formación en lengua y cultura españolas para todos los grupos de edad: Espacio infantil, Educación Infantil, Primaria, Secundaria y personas adultas.

El equipo de Accem en el CETI de Melilla ha desarrollado una programación específica para cada uno de los grupos de edad. En el caso de los alumnos y alumnas me- nores se trabaja mucho con las familias para hacer partícipes a los padres y madres de la educación de sus hijos/as.

\section{CONCLUSIONES}

Las conclusiones obtenidas se presentan respondiendo a cada uno de los objetivos.

- Explicar los fenómenos de violencia de género y trata desde las creencias patriarcales.

- Los fenómenos de violencia de género $\mathrm{y}$ trata se explican fundamentalmente en el marco de las creencias patriarcales y es lo que permite que la explotación de mujeres y niñas sea un negocio próspero.

- Analizar los conceptos de trata de seres humanos con fines de explotación sexual a la luz de la normativa internacional y nacional:

El término de trata de personas internacionalmente aceptado es el recogido en el Protocolo de Palermo (2000).

Tanto los documentos europeos como los nacionales toman la definición de trata de seres humanos con fines de explotación sexual registrada en el Protocolo de Palermo (2000, p.2) (Art. 3). A excepción del Plan Integral de lucha contra las mujeres y niñas con fines de explotación sexual (2015, p.7) que toma la definición de trata del artículo 177 bis del Código Penal. Dicho artículo supone el registro de la definición de trata de personas del Protocolo de Palermo en el Código Penal del Estado Español. 
El Decreto No 266 del 5 de mayo de 2015 de la Ciudad de Melilla no recoge una definición de trata de seres humanos para estos fines. Este recoge medidas de represión y desviación de actos sexuales y de la prostitución en determinadas zonas del escenario público.

Se puede concluir que después de dieciocho años del Protocolo de Palermo (2000) no se ha avanzado en matizar el concepto de víctima de trata y que sigue existiendo confusión terminológica en toda la normativa analizada.

La trata de seres humanos no puede ser reducida meramente a un problema de migración ilegal, de orden público, de delincuencia organizada o prostitución, para estudiar y proyectar un plan de acción para combatirla, sino que debe integrar todos los ámbitos que comprende y tener presentes los Derechos Humanos Universales. Todo plan de acción contra la trata de seres humanos que se planifica y ejecuta sin tener en cuenta todos los ámbitos que acapara, no dispondrá de la capacidad suficiente para identificar a las víctimas propias de la trata. Y por consiguiente, no se les serán dispensadas su correspondiente asistencia y protección adecuadas a sus necesidades.

- Identificar los Derechos Humanos Universales vulnerados en la trata de personas con fines de explotación sexual: Desmenuzando cada una de las características de la definición recogi- da en el Protocolo de Palermo (2000, p.2). Los Derechos Humanos Universales vulnerados son los siguientes: 1 , $5,2,4,12,7,13$ y 22.

La reflexión propositiva que consideramos importante aportar sobre el tema tratado es la siguiente: Los planes de acción de lucha contra la trata de personas con fines de explotación sexual deberían recoger la definición con su clara diferenciación con los términos de prostitución y tráfico de personas; teniendo siempre presentes todos los ámbitos que la trata comprende, y no solo el de la prostitución; y poniendo en valor todos y cada uno de los Derechos Humanos Universales vulnerados en el desarrollo de la misma.

- Visualizar la situación de las personas migrantes en Melilla y en su entorno geográfico.

Ni el gobierno de la Ciudad Autónoma de Melilla ni la Delegación del Gobierno han desarrollado un plan de acción contra la trata hasta el momento.

Existe el Decreto No. 266 de fecha de 5 de mayo de 2015 para la garantía de la convivencia ciudadana y la protección del espacio urbano, por el que se desplazan los actos de prostitución a más de $200 \mathrm{~m}$ de las zonas de actividad docente y empresarial.

Y el Protocolo Interinstitucional de actuación en materia de violencia de género (2014) por el que las mujeres extranjeras que se encuentren inmersas en una red de trata 
podrán realizar la denuncia oportuna de la situación que viven sin el temor de ser detenidas y/o repatriadas. Sin embargo, este protocolo no contempla medidas específicas para poder ayudar a estas víctimas a realizar dicha denuncia y poder salir de su situación de explotación.

Las personas migrantes que logran llegar a Marruecos sortean la frontera con Melilla de diferente forma. Las personas sirias intentan pasar por el puesto fronterizo de Beni-Enzar colándose sin ser vistas por la policía marroquí, o, pagando a mafias. Una vez en Melilla pueden solicitar protección internacional en las oficinas de la Policía Nacional. Se les hará una entrevista, en la que estará presente, un/a policía, un/a traductor/a y un/a abogado/a; a veces también está presente ACNUR.

Los varones subsaharianos suelen saltar la valla; las mujeres subsaharianas suelen hacerlo en patera.

Las personas sirias suelen instalarse en hostales de la ciudad de Nador. Las subsaharianas viven escondidas en los montes. Allí son atendidas de manera sanitaria por la labor de la Delegación de Migraciones del servicio Jesuita.

Una vez que logran tocar suelo melillense son trasladados al CETI, donde todas estas personas serán entrevistadas, se les dará una tarjeta identificatoria, pasarán por un reconocimiento médico, unas charlas de información de normas del Centro y por la escuela de formación.

\section{REFERENCIAS BIBLIOGRÁFICAS}

$\mathrm{ACNUR}^{13}$. (1967). Protocolo sobre el Estatuto de los Refugiados. Recuperado de https://www.acnur.org/5bo76dcd4.pdf

Amnistía Internacional. (2015). Informe 2015/16. La situación de los Derechos Humanos en el mundo. Recuperado de file://C:/Documents\%2oand\%2oSettings/Usuario/Mis\%2odocumentos/ Downloads/POL1025522016SPANISH. PDF

Ayuntamiento de Sevilla. (2010). Ordenanza para luchar contra la prostitución y la trata confines de explotación sexual en la ciudad de Sevilla. Recuperado de http:// www.sevilla.org/ayuntamiento/areas/ area-de-familia-asuntos-sociales-y-zonas-de-especial-actuacion/a-mujer/ plan-integral-contra-la-prostitucion/ ordenanza-para-luchar-contra-la-prostitucion-y-la-trata-con-fines-de-explotacion-sexual-en-la-ciudad-de-sevilla

Brownmiller, S. (1975). Against our will: Men, women, and rape. New York: Simon \& Schuster.

BOE. (1995). Ley Orgánica 10/1995, de 23 de noviembre, del Código Penal. Núm. 281 - 25444. Recuperado de http:// www.boe.es/boe/dias/1995/11/24/pdfs/ A33987-34058.pdf

BOE. (2000). Ley Orgánica 4/200o, de 11 de enero, sobre derechos y libertades de los extranjeros en España y su integración social. Núm. 10 - 544. Recuperado de http://www.boe.es/boe/ dias/2000/o1/12/pdfs/A01139-01150. pdf

13 Alto Comisionado de Naciones Unidas para los Refugiados. 
BOE. (2009). Real Decreto 1162/2009, de 10 de julio, por el que se modifica el Reglamento de la Ley Orgánica 4/200o, de 11 de enero, sobre derechos y libertades de los extranjeros en España y su integración social, aprobado por el Real Decreto 2393/2004, de 30 de diciembre. Núm. 177- 12208. Recuperado de http://wwwo4/04/ 2oboe.es/boe/dias/2009/07/23/pdfs/ BOE-A-2009-12208.pdf

BOE. (2010). Ley Orgánica 5/2010, de 22 de junio, por la que se modifica la Ley Orgánica 10/1995, de 23 de noviembre, del Código Penal. Núm. 152 - 9953. Recuperado de http://www. boe.es/boe/dias/2010/o6/23/pdfs/ BOE-A-2010-9953.pdf

BOE. (2011). Real Decreto 557/2011, de 20 de abril por el que se aprueba la Ley Orgánica 4/200o, de 11 de enero, sobre derechos y libertades de los extranjeros en España y su integración social tras su reforma por Ley Orgánica 2/2009. Núm. 103 - 7703. Recuperado de https://www.boe.es/buscar/act.php?id=BOE-A-2011-7703

BOE. (2015). Ley 4/2015, de 27 de abril, del Estatuto de la víctima del delito. Núm. 101 - 36569. Recuperado de https:// www.boe.es/boe/dias/2015/04/28/ pdfs/BOE-A-2015-4606.pdf

BOME. (2015). Decreto $\mathrm{N}^{\circ} 266$ de fecha 5 de mayo, relativo a aprobación definitiva del Reglamento para la garantía de la convivencia ciudadana y la protección del espacio urbano en la Ciudad Autónoma de Melilla. Núm. 5233 - 2721. Recuperado de http://www.melilla.es/melillaportal/ contenedor.jsp?seccion=ficha_bome. jsp\&dboidboletin $=210329 \& \operatorname{cod} R e-$ $\mathrm{si}=1$ \&language $=\mathrm{es} \& \operatorname{cod}$ Adirecto $=15$

Comisión Europea. (2012). Comunicación de la Comisión al Parlamento Europeo, al Consejo, al Comité Económico y Social Europeo y al Comité de Las Regiones. Estrategia de la UE para la erradicación de la trata de seres humanos (2012-2016). Recuperado de https://www.policia.es/ trata/pdf/lexuriserv.pdf

Comisión Europea. (2016). Informe de la Comisión al Parlamento Europeo y al Consejo. Informe sobre los progresos realizados en la lucha contra la trata de seres humanos (2016) con arreglo al artículo 20 de la Directiva 2011/36/UE relativa a la prevención y lucha contra la trata de seres humanos y a la protección de las víctimas \{SWD (2016) 159 final\}. Recuperado de https://eur-lex.europa.eu/legal-content/ES/TXT/?uri=CELEX\%3A52016DCo267

Consejería de Bienestar Social y Sanidad. (2013). Plan local de inclusión social de la Ciudad de Melilla (2013-2017). Recuperado de https://eapnmelilla.files.wordpress.com/2011/01/plan_local_inclusion.pdf

Consejo de Europa. (2000). CARTA DE LOS DERECHOS FUNDAMENTALES DE LA UNIÓN EUROPEA. Recuperado de http://www.europarl.europa.eu/charter/pdf/text_es.pdf

Consejo de Europa. (2005). Convenio del Consejo de Europa sobre la lucha contra la trata de seres humanos. Recuperado de http://www.accem.es/ficheros/documentos/pdf_trata/Convenio_Consejo_de_Europa.pdf 
Consejo de Europa. (2011). DIRECTIVA 2011/36/UE DEL PARLAMENTO EUROPEO Y DEL CONSEJO de 5 de abril de 2011 relativa a la prevención y lucha contra la trata de seres humanos y a la protección de las víctimas y por la que se sustituye la Decisión marco 2002/629/ JAI del Consejo. Recuperado de https:// eur-lex.europa.eu/legal-content/ES/ TXT/PDF/?uri=CELEX:32011Loo36\&from $=\mathrm{ES}$

Consejo de Europa. (2012). Directiva 2012/29/UE del Parlamento europeo y del Consejo de 25 de octubre de 2012 por la que se establecen normas mínimas sobre los derechos, el apoyo y la protección de las víctimas de delitos, y por la que se sustituye la Decisión marco 2001/220/ JAI del Consejo. Recuperado de https:// eur-lex.europa.eu/legal-content/es/TX$\mathrm{T} /$ ?uri=CELEX\%3A32012L0029

Consejo de la Unión Europea. (2002). Decisión marco del Consejo de 19 de julio de 2002 relativa a la lucha contra la trata de seres humanos. Recuperado de https:// eur-lex.europa.eu/legal-content/ES/ TXT/?uri=CELEX\%3A32002Fo629

Defensor del Pueblo. (2012). La trata de seres humanos en España: Víctimas invisibles. Recuperado de http://www.defensordelpueblo.es/es/Documentacion/ Publicaciones/monografico/contenido_1348128571191.htmle

Defensor del Pueblo. (2013). La trata de seres humanos en España: Víctimas invisibles. Recuperado de https://www. defensordelpueblo.es/informe-anual/ informe-anual-2013/

Instituto Andaluz de la Mujer. (2011). Estudio sobre las mujeres víctimas de trata con fines de explotación sexual en Andalucía. Sevilla, España.

Lázaro, A. (2014). La nueva Constitución del Reino de Marruecos. Revistas de Estudios Políticos, 131, 127-138. Recuperado de https://dialnet.unirioja.es/ejemplar/385385

Marques y Osborne (1991). Sexualidad y sexismo. Madrid. Fundación Universidad - Empresa.

Ministerio de Igualdad (2009). Plan integral contra la trata de seres humanos. Madrid. Disponible en: https://www.bienestaryproteccioninfantil.es/imagenes/ tablaContenidoso3SubSec/Plan_integral_contra_trata_de_seres_Humanos. pdf

Ministerio de Sanidad, Servicios Sociales e Igualdad (2015). Plan Integral de lucha contra la trata de mujeres y niñas con fines de explotación sexual (20152018). Recuperado de http://www. violenciagenero.msssi.gob.es/planActuacion/planContraExplotacionSexual/ docs/Plan_Integral_trata_18_Septiembre2015_2018.pdf

Ministerio de Empleo y Seguridad Social. (2011). Protocolo para la detección y actuación ante posibles casos de trata de seres humanos con fines de explotación sexual.

Ministerio de Sanidad, Servicios Sociales e Igualdad. (2013). Estrategia nacional para la erradicación de la violencia contra la mujer (2013-2016). Recuperado de http://www.violenciagenero.msssi.gob. es/planActuacion/estrategiaNacional/ home.htm

Ministerio del interior. (2007). Plan integral de lucha contra la trata de seres humanos 
con fines de explotación sexual. Análisis de situación y plan de actuación. Recuperado de http://www.intermigra.info/ extranjeria/archivos/impresos/PlantrataMIR.pdf

Naciones Unidas (1985). III Conferencia Mundial para revisar y evaluar los logros del Decenio de las Naciones Unidas para la Mujer: Igualdad, Desarrollo y Paz. Nairobi. Disponible en: https://www. un.org/womenwatch/daw/beijing/ otherconferences/Nairobi/Nairobi\%20 Full\%20Optimized.pdf

Naciones Unidas. (1948). La Declaración Universal de los Derechos Humanos. Recuperado de https://www.un.org/es/ universal-declaration-human-rights/

Naciones Unidas. (2000). Protocolo para prevenir, reprimir y sancionar la trata de personas, especialmente mujeres y niños. Recuperado de https://www.ohchr. org/documents/professionalinterest/ protocoltraffickinginpersons_sp.pdf

Naciones Unidas. (2009). Manual contra la trata de personas. Recuperado de https://www.unodc.org/documents/ human-trafficking/o7-89378_spanish_E-Book.pdf

Viceconsejería de la Mujer. (2014). Protocolo Interinstitucional de Actuación en Materia de Violencia de Género de la Ciudad Autónoma De Melilla. Recuperado de https://www.melilla.es/melillaportal/RecursosWeb/DOCUMENTOS/1/o_12080_1.pdf

\section{PARA CITAR ESTE ARTícULO}

Lara Palacios, M., Monreal Gimeno, M. Del C., y Sánchez Fernández, S. (2019). Violencia de género y trata de personas con fines de explotación sexual. Collectivus, Revista de Ciencias Sociales, 6(2), 121-140.

DOI: http//dx.doi.org/10.15648/Coll.2.2019.8 